1. Killick, S. C., Indgenious African metallurgy: nature and culture. Annu. Rev. Anthropol., 1993, 22, 317-337.

2. Henshilwood, C. S., d'Errico, F. and Watts, I., Engraved ochres form the middle Stone Age levels at Blombos cave, South Africa. J. Hum. Evol., 2009, 57, 27-47.

3. Schweitzer, P. A., Metallic Materials - Physical, Mechanical and Corrision Properties, Marcel Dekker, New York, USA, 2003.

4. Stalics, A., Metallurgy Made in and for Europe-The Perspective of Producers and End-Users Roadmap, Luxmbourg Publication Office of the European Union, Brussels, 2014.

5. Cunliffe, B., Iron Age Communities in Britian, Routledge Tylor and Francis, Great Britian, UK, 1974.

6. Pollard, A. M. and Brothwell, D. R., Archaeological Sciences, John Wiley, USA, 2001.

7. Vidyadharan, K. T. and Joshi, A., Systematic geological mapping in the Northeasternmos part of Naga Hills ophiolite belt around Chokla-Wui-Kenjong-Chipur-Pang areas, Teunsang district, Nagaland, Geological Survey of India Progress Report (1982-83), 1983.

8. Roy, R. K., Meso-Cenozoic Accretionary Prims on the Margin of Indo-Burman Range Ophiolite and its Implications, Suran Publication, Patna, 1989.

9. Brunnschweiler, R. O., On the geology of Indo-Burman ranges. J. Geol. Soc. Aust., 1966, 13(1), 137-194.

10. Jamir, T., The Ethnography and Archaeology of the Naga Metal Workers: A Case Study on Early Metal Production at Wui Village, Tuensang District (Excavation Report), North East Zone Cultural Centre, Dimapur, Nagaland, 2015.

11. Balasubramaniam, P. D., Characterization of ancient Indian iron and entrapped slag inclusions using electron, photon and nuclear microprobes. Bull. Mater. Sci., 2001, 24, 317-322.

12. Venkannah, S., Metallurgy Lab: Materials Science Module-Mech 2121, Faculty of Engineering, Mechanical and Production Engineering Department, University of Mauritius, 2004; http:// docplayer.net/27437059-Metallurgy-lab-materials-science-mech2121-university-of-mauritius-faculty-of-engineering-mechanicaland-production-engineering-department.html

13. Levi, E. E., Welding advicers.com, 2003; http://www.weldingadvicers.com/

14. Reddy, L. S., Termite mound as an effective geochemical tool in mineral exploration: a study from chromite mining area Karnataka, India. Res. J. Chem. Sci., 2014, V, 85-88.

15. Digges, T. G., Metal laboratory heat treatment, 2012; http://www. metalabheattreat.com

16. Dutta, S. K., Studies on direct reduced iron melting in induction furnace. Trans. Indian Inst. Met., 2004, 57, 467-473.

ACKNOWLEDGEMENTS. Tiatemjen Tzudir thank S.S. for the Internship programme of scientific analysis on Ancient Ceramics; Dr Kanagraj, Department of Mechanical Engineering, IIT Guwahati for providing laboratory facilities; Dr Sachin D. Kore, Department of Mechanical Engineering, IIT Guwahati for guidance; Saiffuddin Ahmed, Rituraj Saikia and the IITG Central Instrument Facility, Charan, Avinish Tiwari, Bikash Kumar, Dr Pankaj Singh, Preyanka and Jeetendra for the support extended.

Received 30 May 2018; revised accepted 4 October 2018

doi: $10.18520 / \mathrm{cs} / \mathrm{v} 116 / \mathrm{i} 2 / 311-319$

\section{A comparison of blood biochemical parameters as a tool to measure welfare in free-ranging red deer (Cervus elaphus elaphus) after chemical and physical restraint}

\author{
Chiara Mariti ${ }^{1}$, Francesca Iacobelli ${ }^{1}$, Eva Ricci ${ }^{1}$, \\ Marco Fusi ${ }^{2}$, Manuel Mengoli ${ }^{3}$, \\ Alessandro Cozzi $^{3}$ and Angelo Gazzano ${ }^{1, *}$ \\ ${ }^{1}$ Dipartimento di Scienze Veterinarie-Università di Pisa, Italy \\ ${ }^{2}$ DEFeNS-Università di Milano, Italy \\ ${ }^{3}$ IRSEA, Institut de Recherche en Sémiochimie et Ethologie Appliquée, \\ Apt, France
}

Eighteen red deer were captured in box traps and then physically restrained in an immobilizing box; three red deer were captured twice, once by chemical restraint (anesthetized with a mixture of Xylazine, Tiletamine and Zolazepam) and once in the immobilizing box. It was found that microhaematocrit, total erythrocyte and leukocyte counts, as well as plasma cortisol, were higher after the physical restraint. Anserine and 3-methyl-L-histidine concentrations were higher after the physical restraint in animals undergoing both captures. Data supports previous studies indicating that the physical restraint after capture is more stressful than the chemical one. Anserine and 3-methyl-L-histidine were higher after the physical restraint in red deer undergoing both methods, suggesting that measuring plasma aminoacyl-imidazole dipeptides and their components may be important in stressed animals prone to capture myopathy.

Keywords: Aminoacyl-imidazole dipeptides, anesthesia, animal welfare, red deer, restraint, stress.

NOWADAYS control and stewardship of deer populations is a complex social, economic, political and biological issue. When free-ranging red deer are overabundant, as occurs in some areas of Italy, their number is usually controlled. Live capture may be more socially acceptable or practical than hunting or sharp-shooting in restricted areas $^{1}$.

The capture and immobilization of wild ungulates, carried out to monitor, treat and move animals, are likely to be stressful events for these animals ${ }^{2}$. This is clearly indicated by behavioural evaluations, sudden deaths, as well as changes induced in various haematological and biochemical blood constituents ${ }^{3,4}$. However, these changes differ considerably according to the methods of capture and restraint used ${ }^{2}$. A remarkable difference in concentration of blood constituents is observed when comparing physical and chemical capture methods ${ }^{5-8}$. The physical

*For correspondence. (e-mail: angelo.gazzano@unipi.it) 
method consists of box traps or nets, e.g. netted cage traps $^{1}$, the helicopter and net-gun capture technique ${ }^{9}$; whereas the chemical method involves a mixture of anaesthetics ${ }^{2,10-12}$. Therefore, besides the capture itself, animals captured through both methods may be exposed to restraint, transport or management, which can cause stress $^{13}$ and reduce animal welfare ${ }^{14}$. In some cases, animals after being released may die from capture myopathy ${ }^{9,14-17}$ and from other acute and chronic diseases described by DelGiudice et al. ${ }^{18}$.

In ungulates, acute and chronic stressors lead to large biochemical changes. Acute stress leads to an increase in plasma cortisol ${ }^{19}$, release of growth hormone $(\mathrm{GH})$, thyroid stimulating hormone (TSH), glucagon and glucose in the blood $^{20}$, an increase in haematocrit and in the total number of erythrocytes ${ }^{2,3,7,9,21}$, a modification of the leukocyte formula ${ }^{2,20,22}$, and possible alterations of the muscle enzymatic profile (transaminases, creatine kinase and lactate dehydrogenase $)^{20,23}$. Those changes are particularly evident in animals subjected to an intense motor activity, as in physical restraint ${ }^{15}$. Chronic stress is usually associated with high adrenal activity, leading to adrenal hypertrophy, thymus involution, lymphopenia, eosinopenia and neutrophilia ${ }^{13}$. Moreover, high adrenal activity is associated with increase in the animal's susceptibility to infectious diseases and, particularly in wild animals, may result in the activation of latent infections ${ }^{24}$.

Aminoacyl-imidazole dipeptides (carnosine, anserine, L-histidine and 3-methyl-L-histidine) occur in the skeletal muscle of many mammals, particularly in those adapted to either high-speed running or to prolonged periods of hypoxia, working as $\mathrm{H}^{+}$buffers over the physiological $\mathrm{pH}$ range during muscle contraction ${ }^{25-27}$.

A previous study ${ }^{28}$ suggests that in rabbits, carnosine and anserine are released into blood after muscular shock, thus providing information on the degree of muscular lesion. Moreover, Dunnett et al. ${ }^{29}$ showed that intense exercise resulted in a significant increase in plasma carnosine concentration in thoroughbred horses, and greater increases were observed following the onset of exerciseinduced rhabdomyolysis. The urinary excretion of 3methyl-L-histidine has been accepted as a valid measure of muscle protein breakdown in vivo in rats, humans and cattle $^{30-32}$. Similar to other wild animals, red deer requires management that aims to reduce the potentially harmful, stress-related responses ${ }^{33}$, because captures can be extremely distressing, even leading to death within days or hours ${ }^{14}$. Interventions such as captures are normally carried out for animal management. Opportunistic studies can take advantage of their execution to acquire scientific information, reducing the number of animals used for research purposes and thus being more ethically acceptable.

The aim of the current study was to compare blood biochemical parameters and plasma cortisol in free-ranging captured red deer (Cervus elaphus elaphus) restrained by chemical or physical methods. In addition, plasma ami- noacyl-imidazole dipeptides and their components (carnosine, anserine, L-histidine, 3-methyl-L-histidine) were examined as a possible tool to assess muscular stress (i.e. myolysis) related to capture.

The study was carried out in collaboration with and within a national park in central Italy - the Foreste Casentinesi, Monte Falterona and Campigna Park (lat.: 43.8433333; long: 11.7911111). The animals involved in this study were captured and clinically assessed in order to be moved for restocking in other Italian parks, the procedures were thus not carried out for research purposes. No animal care license nor approval of ethical committees was therefore needed.

For this opportunistic study, a convenience sample of 22 free-ranging red deer (Cervus elaphus elaphus), 12 females and 10 males, not used to the presence of humans, were involved. Regarding age, 16 were adult (more than 14 months) and 6 were young (10-14 months). Seven were captured during $7: 00-9: 00$ (morning) and 15 between 13:00-15:00 (afternoon); 9 were captured in springtime, 10 in autumn and 3 in winter. Captures occurred between March 2007 and November 2008, excluding the season of late pregnancy-lactation (late spring-summer). All the animals appeared to be in good health (without injuries, showing a normal locomotion and a good body condition) at the time of capture.

For the capture, a wide-fenced half-woody area (about 10,000 sq. m) was prepared (Figure 1), within which baits (fruits and salt) and a trap was set-up. The trap was located at the opposite side of the entrance door, where the trees were more dense and the fence was narrow. The trap consisted of three parts (see Figure 2): a capture box, a tunnel and an immobilizing box. The latter was $3 \mathrm{~m}$ high and $3 \mathrm{~m}$ long; as for the width, it was provided with a sliding wall which restricted the animal until blocking it. One of the lateral panels had a wide window for marking, horn cutting in males, radio collar fitting and blood sampling.

The fence was equipped with a photocell system, which closed the entrance when the deer was completely inside. When an animal was captured, a team of six people arrived, including a veterinarian responsible for anaesthesia, biometric measurements, marking (putting a tag on one or both ears), administering spray antibiotics on skin injures and blood sampling. The team arranged themselves in a row to push the deer towards the trap.

In the capture box, animals subjected to chemical restraint were anaesthetized with a mixture of xylazine, tiletamine and zolazepam Rompun $^{\circledR}+$ Zoletil $^{\circledR}$ ). The anaesthetic dose was calculated based on the deer's estimated weight and, as suggested by Rosef et al. ${ }^{11}$, was approximately $250 \mathrm{mg}$ of xylazine and $250 \mathrm{mg}$ of tiletamine and zolazepam per $100 \mathrm{~kg}$ body mass. This mixture was injected using a dart, shot by a veterinarian through a blowgun. The veterinarian was positioned with good visibility, at a sufficient distance from the trap, not to 


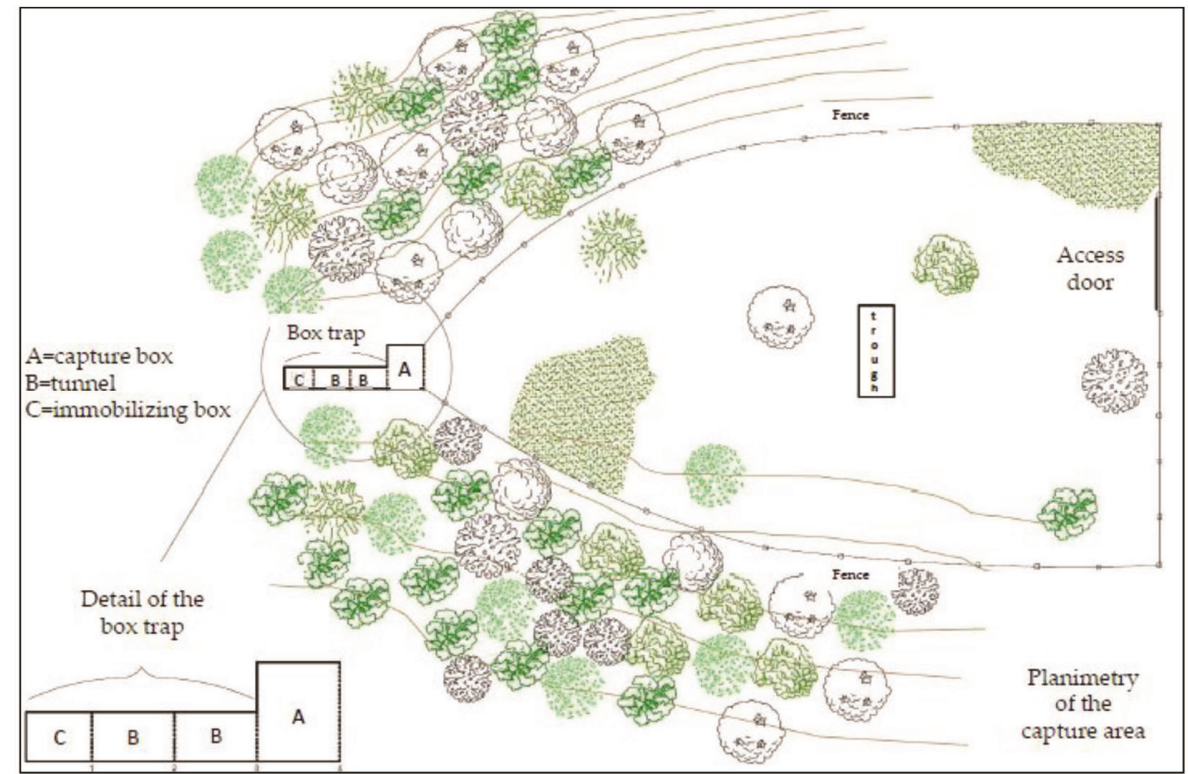

Figure 1. Planimetry of the capture area with details of the box trap, where physical and chemical restraints were carried out.

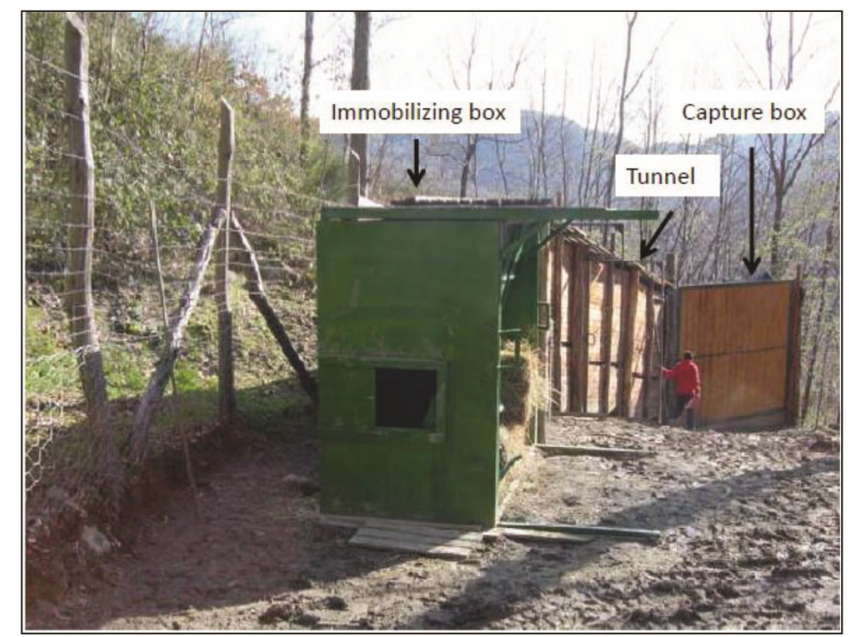

Figure 2. Details of the box trap, with the distinction between capture box, tunnel and immobilizing box.

cause panic in the animals. The time from injection to complete immobilization with head down varied from 3 to $10 \mathrm{~min}$ and none of the animals showed signs of panic. Anaesthetized animals were blindfolded and then their legs were tied. The level of anaesthesia was monitored through assessment of heart rate, respiratory rate, oxygen saturation, absence/presence of reflexes (corneal, auricular and lingual) and response to external stimuli. The entire process lasted approximately $25 \mathrm{~min}$. Monitoring was carried out until the deer was able to stand. Recovery time after the end of the clinical operations was variable, up to $10 \mathrm{~min}$.

Four animals (three females and one male, 84.2 \pm $7.2 \mathrm{~kg}$ ) were captured this way. One of the animals died immediately after injecting the anaesthetics; it was not possible to perform a necropsy to clarify the cause of death. The remaining three subjects were recaptured three days later and subjected to physical restraint described below.

The same box traps were used to capture the other 18 animals (nine females and nine males, $101.3 \pm 12.6 \mathrm{~kg}$ ), restrained with a physical method. The capture was the same as described for the chemical method, but it differed starting from the moment the deer entered the capture box. Animals in this group were in fact moved through the tunnel to the immobilizing box. All the animals underwent the same procedures, except those related to anaesthesia. The procedures took approximately $10 \mathrm{~min}$.

The final number of blood samples was 24 , due to the death of one subject after injecting the anaesthetics. Blood samples were taken at the end of all procedures. Each sample consisted of $10 \mathrm{ml}$ of blood collected from the jugular vein in a vacutainer tube containing EDTA and immediately put in an ice bath.

At the capture site, $9 \mathrm{ml}$ of blood was centrifuged at $3000 \mathrm{rpm}$ for six minutes. Plasma and the remaining blood were carried in an ice bag to the laboratory where analyses were performed. The whole blood was used to determine: micro haematocrit $(\%)$, using a capillary tube; total number of erythrocytes (RBC) and leukocytes (WBC), using a Thoma-Zeiss ${ }^{\circledR}$ counting chamber; and leukocyte formula, assessed through blood smear with a Differential Quik Stain Kit ${ }^{\circledR}$. Plasma was used to measure plasma aminoacyl-imidazole dipeptides and their components (carnosine, anserine, L-histidine and 3-methyl-Lhistidine) using high-performance liquid chromatography (HPLC), as previously described ${ }^{28}$. Plasma was also used 
to measure cortisol using a direct immunoenzymatic assay $\left(\right.$ DiaMetra $\left.^{\circledR}\right)$.

The statistical analysis was carried out in three steps. For the data obtained by animals captured through the physical method $(n=21)$, we tested the statistical differences among the categorical explanatory variables: sex (levels: males/females); age (levels: young/adults); time of sampling (levels: morning/afternoon); season (levels: spring/autumn/winter). All the variables were considered fixed and orthogonal. Data obtained from animals of the chemical group $(n=3)$ were compared to those of the physical group ( $n=18$; for cortisol $n=15$ because the values were not determinable for three animals). For this analysis, in order to have independent data, the samples of deer captured through both methods were not taken into account. Data obtained from animals captured using both methods $(n=3)$ were instead compared as paired data. The capture method was considered as an orthogonal and fixed factor.

Because of the nonparametric distribution of all the variables studied, a permutational multivariate analysis of variance (PERMANOVA) was performed. Significance was set at $P<0.05$. The software used for analysis of variance was PERMANOVA ${ }^{34,35}$ for PRIMER 6 routines $^{36}$.

All the data, except for the leukocyte formula, were analysed through univariate analysis of variance (ANOVA, $P<0.05$ ). As the data expressed as a percentage for the leukocyte formula are compositional, they were made independent using Aitchison's transformation $^{37}$ : New Neutr. $=$ Ln(Neutr. $)-(($ Ln $($ Neutr. $)+$ Ln $($ Linf. $)+\operatorname{Ln}($ Eosin. $+\operatorname{Ln}($ Mon. $)) / 4)$. Data were then normalized before being statistically analysed by multivariate analysis of variance (MANOVA, $P<0.05$ ).

The analysis of haematological and biochemical variables in subjects captured by the physical method did not reveal any statistical difference for the factors sex, age, time of sampling, and season (the only exception was 3-methyl-L-histidine, higher in males: $3.33 \pm$ $1.61 \mathrm{nmol} / \mathrm{ml}$ versus $6.21 \pm 2.59 \mathrm{nmol} / \mathrm{ml} ; \quad F=9.5658$, $P=0.006)$. Thus, such factors were not considered in further analyses.

Data obtained on micro-haematocrit, RBC, WBC, plasma cortisol, plasma aminoacyl-imidazole dipeptides and their components, as well as the results of the statistical analysis are summarized in Table 1 (chemical versus physical capture method, excluding subjects undergoing both methods) and Table 2 (chemical versus physical capture method in subjects undergoing both methods). In both comparisons, microhaematocrit, $\mathrm{RBC}, \mathrm{WBC}$ and plasma cortisol were found to be higher after the physical restraint than after the chemical restraint. Moreover, anserine and 3-methyl-L-histidine were higher after the physical restraint in red deer undergoing both methods. For 3-methyl-L-histidine, a strong tendency for higher values was also found in subjects restrained by the physi- cal method compared to subjects restrained by the chemical method.

In the current study it was found that physical restraint, compared to chemical restraint, led to higher haematocrit and number of erythrocytes. These results are in line with previous studies on red deer ${ }^{2,5}$, wild impala ${ }^{38}$, whitetailed deer ${ }^{7}$ and Spanish ibex ${ }^{8}$. On the one hand, a major contribution to the observed changes in RBC and haematocrit may be due to the catecholamine release during physical restraint and consequent spleen contraction ${ }^{2}$. In fact during capture by physical means, spleen contraction was found to be responsible for $40 \%$ of the blood cell count increase 5 . On the other hand, $\alpha-2$ adrenergic agonists (such as xylazine, used in this study) initially increase blood pressure, followed by long-term hypotension and the entrance of interstitial fluid into the circulatory system to stabilize blood ${ }^{11,39}$. The latter could have partially reduced the haematic values after the chemical capture.

The influence of different kinds of capture on WBC has not yet been completely clarified. Arnemo et al. ${ }^{10}$ and Topal et al. ${ }^{40}$ did not find any differences when comparing physical and chemical captures in red deer, whilst Cross et $a l .{ }^{5}$ in red deer and Peinado et al. ${ }^{8}$ in Spanish ibex found higher values after the physical technique. The current study supports the latter results. A decrease in the lymphocyte count and a mild decrease in eosinophils were also observed in subjects undergoing both methods of restraint. Such changes are likely due to the action of catecholamines, typically released in acute stress. As for the leukocyte formula, data of the current study revealed statistical significant differences only when comparing subjects that underwent both restraint methods. The lack of difference for the other comparison may be due to the high individual variability of this parameter, highlighting the importance of using paired data when the sample is small. Specifically, after physical restraint, animals presented significantly higher values of neutrophils and monocytes, and lower values of lymphocytes and eosinophils. These results are in agreement with $\mathrm{Cuomo}^{20} \mathrm{re}-$ garding stress in ungulates and with Taylor ${ }^{22}$ on cattle excitement and stress, whilst Marco and Lavín ${ }^{2}$ found lymphocytosis rather than lymphopenia in red deer. However, when comparing results from different studies, the exact procedure used for physical and chemical captures should be taken into account, as it is possible that slight methodological differences can affect haematic parameters $^{7}$. In any case, it is unlikely that the use of anaesthetics such as xylaxine affected the leukocytes formula, as xylaxine is a $\alpha-2$ adrenergic agonist, while the mobilization of neutrophils and lymphocytes in acute stress is due to the activation of beta receptors ${ }^{41}$.

As in previous studies on white-tailed deer $^{6}$ and wild impala $^{38}$, the current one found that plasma cortisol was higher after physical than after chemical restraint. An increase in plasma cortisol is typically associated with 


\section{RESEARCH COMMUNICATIONS}

Table 1. Comparisons between chemical and physical restraint method and relative results of the statistical analysis, excluded data regarding three subjects undergoing both methods

\begin{tabular}{|c|c|c|c|c|}
\hline Variable & $\begin{array}{l}\text { Chemical method } \\
(n=3 ; \text { mean } \pm \mathrm{SD})\end{array}$ & $\begin{array}{c}\text { Physical method } \\
(n=18 ; \text { mean } \pm \text { S.D })\end{array}$ & \multicolumn{2}{|c|}{ Statistical analysis } \\
\hline Microhaematocrit (\%) & $30.67 \pm 3.06$ & $42.72 \pm 6.85^{\mathrm{a}}$ & $F=12.89$ & $P=0.002$ \\
\hline $\mathrm{RBC}\left(\times 10^{6} / \mu \mathrm{l}\right)$ & $5.25 \pm 0.95$ & $7.46 \pm 1.39^{\mathrm{a}}$ & $F=10.8$ & $P=0.004$ \\
\hline WBC $\left(\times 10^{3} / \mu 1\right)$ & $4.73 \pm 2.66$ & $7.43 \pm 2.42^{\mathrm{a}}$ & $F=4.95$ & $P=0.040$ \\
\hline Plasma cortisol (nmol/1) & $89.94 \pm 43.53$ & $803.16 \pm 357.91^{\mathrm{a}, \mathrm{b}}$ & $F=15.27$ & $P=0.001$ \\
\hline Carnosine $(\mathrm{nmol} / \mathrm{ml})$ & $15.41 \pm 12.11$ & $20.77 \pm 13.20$ & $F=1.52$ & $P=0.281$ \\
\hline L-histidine (nmol/ml) & $254.94 \pm 97.83$ & $370.52 \pm 116.90$ & $F=3.92$ & $P=0.850$ \\
\hline Anserine $(\mathrm{nmol} / \mathrm{ml})$ & $33.26 \pm 8.19$ & $60.01 \pm 45.11$ & $\mathrm{~F}=1.14$ & $P=0.310$ \\
\hline 3-Methyl-L-histidine (nmol/ml) & $2.28 \pm 0.15$ & $4.51 \pm 2.70$ & $F=3.99$ & $P=0.060$ \\
\hline Leukocyte formula & & & $F=1.29$ & $P=0.260$ \\
\hline Neutrophils (\%) & $39.00 \pm 7.21$ & $52.72 \pm 6.76$ & & \\
\hline Lymphocytes (\%) & $55.33 \pm 6.66$ & $40.00 \pm 6.32$ & & \\
\hline Eosinophils (\%) & $3.33 \pm 0.58$ & $2.89 \pm 3.01$ & & \\
\hline Monocytes (\%) & $2.33 \pm 1.15$ & $4.39 \pm 2.52$ & & \\
\hline
\end{tabular}

${ }^{\text {a }}$ Statistically significant difference; $b=15$ subjects.

Table 2. Comparisons between chemical and physical restraint method and relative results of the statistical analysis in three subjects undergoing both methods

\begin{tabular}{|c|c|c|c|c|}
\hline Variable & $\begin{array}{l}\text { Chemical method } \\
(n=3 ; \text { mean } \pm \mathrm{SD})\end{array}$ & $\begin{array}{c}\text { Physical method } \\
(n=3 ; \text { mean } \pm \text { S.D })\end{array}$ & \multicolumn{2}{|c|}{ Statistical analysis } \\
\hline Microhaematocrit (\%) & $30.67 \pm 3.06$ & $47.33 \pm 1.15^{\mathrm{a}}$ & $F=78.12$ & $P=0.001$ \\
\hline $\mathrm{RBC}\left(\times 10^{6} / \mu \mathrm{l}\right)$ & $5.25 \pm 0.95$ & $8.84 \pm 1.35^{\mathrm{a}}$ & $F=14.18$ & $P=0.022$ \\
\hline $\mathrm{WBC}\left(\times 10^{3} / \mu \mathrm{l}\right)$ & $4.73 \pm 2.66$ & $11.07 \pm 2.37^{\mathrm{a}}$ & $F=9.50$ & $P=0.036$ \\
\hline Plasma cortisol (nmol/1) & $89.94 \pm 43.53$ & $355.63 \pm 156.51^{\mathrm{a}}$ & $F=8.02$ & $P=0.047$ \\
\hline Carnosine $(\mathrm{nmol} / \mathrm{ml})$ & $15.41 \pm 12.11$ & $6.46 \pm 3.35$ & $F=1.52$ & $P=0.281$ \\
\hline L-histidine (nmol/ml) & $254.94 \pm 97.83$ & $352.66 \pm 110.39$ & $F=1.32$ & $P=0.308$ \\
\hline Anserine $(\mathrm{nmol} / \mathrm{ml})$ & $33.26 \pm 8.19$ & $85.31 \pm 10.59^{\mathrm{a}}$ & $F=45.34$ & $P=0.002$ \\
\hline 3-methyl-L-histidine (nmol/ml) & $2.28 \pm 0.15$ & $5.86 \pm 0.71^{\mathrm{a}}$ & $F=73.71$ & $P=0.001$ \\
\hline Leukocyte formula & & & $F=6.79$ & $P=0.019^{\mathrm{a}}$ \\
\hline Neutrophils (\%) & $39.00 \pm 7.21$ & $69.00 \pm 4.58$ & & \\
\hline Lymphocytes (\%) & $55.33 \pm 6.66$ & $25.00 \pm 5.20$ & & \\
\hline Eosinophils (\%) & $3.33 \pm 0.58$ & $1.67 \pm 0.58$ & & \\
\hline Monocytes (\%) & $2.33 \pm 1.15$ & $4.33 \pm 1.15$ & & \\
\hline
\end{tabular}

${ }^{\mathrm{a}}$ Statistically significant difference.

physiological and psychological stress ${ }^{19}$, suggesting that physical restraint is more stressful than chemical one for red deer. Previous studies reported an increase in plasma cortisol in deer from 10 up to 180 min after ACTH injection $^{42}$. In the present study, the duration of restraint plus the capture were within this time frame, and therefore the time of blood sampling for both restraint methods was considered reliable.

Results of the current study agree with most previous studies on red deer and similar species: physical restraint seems to be more stressful than chemical restraint for red deer. However, for a better assessment of animal welfare, other parameters need to be taken into account, along with the risks related to anaesthesia. Every capture technique risks injury and mortality to the animal ${ }^{9}$. In the current study, one animal out of four died immediately after the injection of anaesthethics, which corresponds to $25 \%$ of the chemical group and to $4.5 \%$ of the total sample. DelGiudice et al. ${ }^{18}$ found a capture-related mortality of $5.4 \%$ in a wide sample of white-tail deer captured and re-captured primarily using a clover trap. This suggests that both methods have risks and a direct comparison is still difficult. Future studies should better investigate whether the mortality rate differs for the two methods of restraint, in order to understand the significance of this problem and to consider it when carrying out a welfare and risk assessment related to capture.

Note that in the current study, the animals restrained by chemical method were also exposed to close contact with people before being anaesthetized, when they were already in the trap. It is possible that reducing or avoiding this phase would lead to even greater differences in the comparison between chemical and physical restraints.

Research aimed to clarify the effects of stress on individual steps involved in capture would be useful in addressing captures towards the least stressful methods. When possible, animals that need to be often handled (e.g. farmed animals) should get used to human proximity 
and handling procedures. However, this is not possible for wild and free-ranging animals. Thus, other strategies to protect their welfare need to be considered.

The main novelty of this study consisted in measuring plasma concentrations of two plasma aminoacyl-imidazole dipeptides (carnosine and anserine) and their components (L-histidine and 3-methyl-L-histidine) as possible parameters for analysis in animals prone to capture myopathy. Such parameters in fact have been previously measured in other species to gain information on muscular lesions ${ }^{28-31}$. Capture myopathy has not been fully understood, but it is known to be associated with severe stress after capture and restraint ${ }^{19}$. Different capture methods lead to different myopathy rates ${ }^{15}$, which may be minimized by reducing human contact, heat stress, exhaustion and noise during processing ${ }^{9,43}$. In addition, it is known that short, intensive bursts of activity involving large muscle groups contributes to myopathy more than longer and less intense activity ${ }^{15}$. All these premises seem to explain why, in the current study, the deer presented higher levels of plasma aminoacyl-imidazole dipeptides after the physical than after the chemical restraint. These findings seem to support the hypothesis that the 3methyl-L-histidine concentration could be a valid index of muscular damage in red deer, similarly to the urinary excretion of this substance in other species ${ }^{31,32}$.

The half-life of aminoacyl-imidazole dipeptides and their components, e.g. carnosine ${ }^{44}, 3$-methyl-L-histidine ${ }^{45}$, L-histidine $^{46}$ in serum and plasma is reported to be much lower than $12 \mathrm{~h}$ in humans. Considering this short halftime, repeating the measurement after three days (as with the deer who underwent both restraint methods in this study) was considered reliable.

Concerning the higher value of 3-methyl-L-histidine in males compared to females, it is plausible that gender differences exist. In fact, Peñafiel et $a .^{47}$ also found that the content of carnosine and anserine in the skeletal muscle of mice was much higher in males than in females. These authors suggest that such differences may be related to the anabolic action of androgens on skeletal muscle.

As stressed for the leukocyte formula, the lack of difference for the other analysed parameters may be due to the high individual variability. The results of this study should therefore be considered as preliminary. The use of plasma anserine, carnosine and their components as possible indexes of acute stress and capture myopathy in red deer needs to be studied in more depth. Further research, with a higher number of animals and the possibility to check a real association of their values with capture myopathy, should be aimed at finding the physiological range of such parameters and clarifying their relationship with acute stress and muscle damage.

The findings of the current study confirmed that physical restraint, compared to chemical restraint, leads to a higher change in blood biochemical parameters in red deer capture. This suggests that physical restraint is par- ticularly stressful for red deer, a point to be considered when planning captures in wild animals that cannot get used to human presence. Although chemical restraint is less stressful, the use of anaesthesia implies risks up to the death of some subjects.

In addition to the assessment of acute stress through blood biochemical parameters and plasma cortisol, the preliminary data obtained from this study suggests that measuring plasma aminoacyl-imidazole dipeptides and their components may be important in stressed animals prone to capture myopathy.

Conflicts of interest: The authors declare no conflict of interest.

1. VerCauteren, K. C., Beringer, J. and Hygnstrom, S. E., Use of netted cage traps for capturing white-tailed deer. In Mammal Trapping (ed. Proulx), Alpha Wildlife Research \& Management Ltd, Sherwood Park, Canada, 1999, pp. 155-164.

2. Marco, I. and Lavín, S., Effect of the method of capture on the hematology and blood chemistry of red deer (Cervus elaphus). Vet. Sci., 1999, 66, 81-84.

3. Wesson, J. A., Scalon, P. F., Kirpatrick, R. L. and Mosby, H. S., Influence of chemical immobilization and physical restraint on packed cell volume, total protein, glucose, and blood urea nitrogen in blood of white-tailed deer. Can. J. Zool., 1979, 57, 756-767.

4. Wesson, J. A., Scalon, P. F., Kirpatrick, R. L., Mosby, H. S. and Butcher, R. L., Influence of chemical immobilization and physical restraint on steroid hormone levels in blood of white-tailed deer. Can. J. Zool., 1979, 57, 768-776.

5. Cross, J. P., Mackintosh, C. G. and Griffin, J. F. T., Effect of physical restraint and xylazine sedation on haematological values in red deer (Cervus elaphus). Res. Vet. Sci., 1988, 45, 281-286.

6. DeNicola, A. J. and Swihart, R. K., Capture-induced stress in white-tailed deer. Wildl. Soc. B, 1997, 25, 500-503.

7. Kocan, A., Glenn, B. L., Thedford, T. R., Doyle, R., Waldrup, K., Kubat, G. and Shaw, M. G., Effects of chemical immobilization on hematologic and serum chemical values in captive white-tailed deer. J. Am. Vet. Med. Assoc., 1981, 179, 1153-1156.

8. Peinado, V., Fernandez-Arias, A., Viscor, G. and Palomeque, J., Hematology of Spanish ibex (Capra pyrenaica hispanica) restrained by physical or chemical means. Vet. Rec., 1993, 132, 580-583.

9. Webb, S. L., Lewis, J. S., Hewitt, D. J., Hellickson, M. W. and Bryant, F. C., Assessing the helicopter and net gun as a capture technique for white-tailed deer. J. Wildl. Manage., 2008, 72, 310314.

10. Arnemo, J. M., Negard, T. and Søli, N. E., Chemical capture of free-ranging red deer (Cervus elaphus) with medetomidineketamine. Rangifer, 1994, 14, 123-127.

11. Rosef, O., Nystoyl, H. L., Solenes, T. and Arnemo, J. M., Hematological and serum biochemical reference values in free-ranging red deer (Cervus elaphus atlanticus). Rangifer, 2004, 24, 79-85.

12. Taillon, J. and Côté, S. D., Social rank and winter forage quality affect aggressiveness in white-tailed deer fawns. Anim. Behav., 2007, 74, 265-275.

13. Griffin, J. F. T., Stress and immunity: a unifying concept. Vet. Immunol. Immunopathol., 1989, 20, 263-312.

14. Griffin, J. F. T. and Thomson, A. J., Farmed deer: a large animal model for stress. Domest. Anim. Endocrinol., 1998, 15, 445-456.

15. Beringer, J., Hansen, L. P., Wilding, W., Fischer, J. and Sheriff, S. L., Factors affecting capture myopathy in white-tailed deer. $J$. Wildl. Manage., 1996, 60, 373-380. 


\section{RESEARCH COMMUNICATIONS}

16. Conner, M. C., Soutiere, E. C. and Lancia, R. A., Drop-netting deer: costs and incidence of capture myopathy. Wildl. Soc. Bull., 1987, 15, 434-438.

17. Montané, J., Marco, I., Manteca, X., Lopez, J. and Lavín, S., Delayed acute capture myopathy in three Roe Deer. J. Vet. Med. A, 2002, 49, 93-98.

18. DelGiudice, G. D., Sampson, B. A., Kuehn, D. W., Powell, M. C. and Fieberg, J., Understanding margins of safe capture, chemical immobilization, and handling of free-ranging white-tailed deer. Wildl. Soc. Bull., 2005, 33, 677-687.

19. Bateson, P. and Bradshaw, E. L., Physiological effects of hunting red deer (Cervus elaphus). Proc. R. Soc. Lond. Biol. Sci., 1997, 264, 1707-1714.

20. Cuomo, A., Lo Stress da cattura negli ungulati selvatici. In Proceedings of third SIVSANC National Congress, Teramo, Italy, 2006, pp. 33-35.

21. Chapple, R. S., English, A. W., Mulley, R. C. and Lepherd, E. E., Hematology and serum biochemistry of captive unsedated chital deer (Axis axis) in Australia. J. Wildl. Dis., 1991, 27, 396-406.

22. Taylor, J. A., Leukocyte responses in ruminants. In Schalm's Veterinary Hematology (eds Feldman, B. F., Zinkl, J. G. and Jain, N. C.), Lippincott Williams \& Wilkins, Philadelphia, Pennsylvania, 2000, 5th edn, pp. 391-404.

23. Montané, J., Marco, I., Lopez-Olvera, J., Perpinan, D., Manteca, $\mathrm{X}$. and Lavin, S., Effects of acepromazine on capture stress in roe deer (Capreolus capreolus). J. Wildl. Dis., 2003, 39, 375-386.

24. Waas, J. R., Ingram, J. R. and Matthews, L. R., Real-time physiological responses of red deer to translocations. J. Wildl. Manage., 1999, 63, 1152-1162.

25. Aristoy, M. C., Soler, C. and Toldrà, F., A simple, fast and reliable methodology for the analysis of histidine dipeptides as markers of presence of animal origin proteins in feed for ruminants. Food. Chem., 2004, 84, 485-491.

26. Ducci, M. et al., Concentrations of carnosine, anserine, L-histidine and 3-methyl histidine in boar spermatozoa and sheep milk by a modified HPLC method. Pol. J. Vet. Sci., 2006, 9, 159-163.

27. Dunnet, M. and Harris, R. C., High-performance liquid chromatographic determination of imidazole dipeptides, histidine, 1methylhistidine and 3-metilhistidine in equine and camel muscle and individual muscle fibres. J. Chromatogr. B, 1997, 88, 47-55.

28. Kurisaki, E. and Hiraiwa, K., A simple analysis of carnosine and anserine - its application to traumatic shock. Fukushima J. Med. Sci., 1988, 34, 11-19.

29. Dunnett, M., Harris, R. C., Dunnett, C. E. and Harris, P. A., Plasma carnosine concentration: diurnal variation and effects of age, exercise and muscle damage. Equine. Vet. J. Suppl., 2002, 34, 283-287.

30. Harris, C. and Milne, G., The urinary excretion of N-methyl histidine by cattle: validation as an index of muscle protein breakdown. Br. J. Nutr., 1981, 45, 411-422.

31. Haverberg, L. N., Omstedt, P. T., Muno, H. N. and Young, V. R., N-Methylhistidine content of mixed proteins in various rat tissues. BBA-Protein. Struct. $M, 1975, \mathbf{4 0 5}, 67-71$.
32. Young, V. R., Alexis, S. C., Baliga, B. S., Munro, H. M. and Muecke, W., Metabolism of administered 3-methylhistidine. J. Biol. Chem., 1972, 247, 3592-3600.

33. Douglas, S. A., Stevenson, K. E., Knowles, P. J. and Bunn, S. J., Characterization of catecholamine release from deer adrenal medullary chromaffin cells. Neurosci. Lett., 2008, 445, 126-129.

34. Anderson, M. J., A new method for non-parametric multivariate analysis of variance. Austral. Ecol., 2001, 26, 32-46.

35. Anderson, M. J., PERMANOVA: a FORTRAN computer program for permutational multivariate analysis of variance. Department of Statistics, University of Auckland, New Zealand, 2005; https://www. stat.auckland.ac.nz/ mja/prog/PERMANOVA UserNotes.pdf

36. Clarke, K. R. and Gorley, R. N., PRIMER v6. User Manual/ Tutorial, PRIMER-E: Plymouth, UK, 2006.

37. Aitchison, J., The statistical analysis of compositional data (with discussion). J. R. Stat. Soc. B, 1982, 44, 139-177.

38. Hattingh, J., Pitts, N. I. and Ganhao, M. F., Immediate response to repeated capture and handling of wild impala. J. Exp. Zool., 1988, 248, 109-112.

39. Wolkers, J., Wensing, T. and Groot Bruinderink, G. W., Sedation of wild boar (Sus scrofa) and red deer (Cervus elaphus) with medetomidine and the influence on some hematological and serum biochemical variables. Vet. Quart., 1994, 16, 7-9.

40. Topal, A., Gul, N. Y. and Yanik, K., Effect of capture method on hematological and serum biochemical values of Red Deer (Cervus elaphus) in Turkey. J. Anim. Vet. Adv., 2010, 9, 1227-1231.

41. Zieziulewicz, T. J., Mondal, T. K., Gao, D. and Lawrence, D. A., Stress-induced effects, which inhibit host defenses, alter leukocyte trafficking. Cell Stress Chaperones, 2013, 18, 279-291.

42. Bubenik, G. A. and Bartos, L., Cortisol levels in red deer (Cervus elaphus) and fallow deer (Dama dama) after an acute ACTH administration. Can. J. Zool., 1993, 71, 2258-2261.

43. Haulton, S. M., Porter, W. F. and Rudolph, B. A., Evaluating 4 methods to capture white-tailed deer. Wildl. Soc. B, 2001, 29, 255-264.

44. Gardner, M. L., Illingworth, K. M., Kelleher, J. and Wood, D., Intestinal absorption of the intact peptide carnosine in man, and comparison with intestinal permeability to lactulose. J. Physiol., 1991, 439, 411-422.

45. Long, C. L., Haverberg, L. N., Young, V. R., Kinney, J. M., Munro, H. N. and Geiger, J. W., Metabolism of 3-methylhistidine in man. Metabolism, 1975, 24, 929-935.

46. Sitton, N. G., Dixon, J. S., Astbury, C., Francis, R. J., Bird, H. A. and Wright, V., Kinetic investigations into the possible cause of low serum histidine in rheumatoid arthritis. Ann. Rheum. Dis., 1988, 47, 48-52.

47. Peñafiel, R., Ruzafa, C., Monserrat, F. and Cremades, A., Genderrelated differences in carnosine, anserine and lysine content of murine skeletal muscle. Amino Acids, 2004, 26, 53-58.

Received 30 October 2017; revised accepted 28 August 2018

doi: $10.18520 / \mathrm{cs} / \mathrm{v} 116 / \mathrm{i} 2 / 319-325$ 